\title{
Retracted: An Analytical Investigation of Fractional-Order Biological Model Using an Innovative Technique
}

\author{
Complexity \\ Received 3 December 2020; Accepted 2 February 2021; Published 23 February 2021 \\ Copyright (๑) 2021 Complexity. This is an open access article distributed under the Creative Commons Attribution License, which \\ permits unrestricted use, distribution, and reproduction in any medium, provided the original work is properly cited.
}

Complexity has retracted the article titled "An Analytical Investigation of Fractional-Order Biological Model Using an Innovative Technique" [1] due to substantial similarity to a previous work by other authors [2]. The earlier article was not cited, though another article by those authors was cited in passing as reference [40]. The aim and structure of $[1,2]$ is the same, and many of the equations are nearly identical in notation: examples 2 and 3 in each article are essentially the same and example 4 in [1] is very similar to example 1 in [2], with only example 1 in [1] being original.

The authors did not agree to retraction, arguing that [2] relied on their own earlier article that introduced the Iterative Laplace transform method, citing it and using its equations [3]. They said [2] also relied on another article [4]. Code files for Maple worksheets (.mw files) are available in Supplementary Materials.

\section{Supplementary Materials}

Code files for Maple worksheets. (Supplementary Materials)

\section{References}

[1] H. Khan, A. Khan, M. A. Qurashi, B. Dumitru, and R. Shah, "An Analytical Investigation of Fractional-Order Biological Model Using an Innovative Technique," Complexity, vol. 2020, p. 13, Article ID 5047054, 2020.

[2] S. C. Sharma and R. K. Bairwa, "Exact Solution of Generalized Time-Fractional Biological Population Model By Means of the Iterative Laplace Transform Method," International Journal of Mathematical Archive, vol. 5, no. 12, pp. 40-46, 2014.

[3] H. Jafari, M. Nazari, D. Baleanu, and C. M. Khalique, "A new approach for solving a system of fractional partial differential equations," Computers \& Mathematics with Applications, vol. 66, no. 5, pp. 838-843, 2013.

[4] A. M. A. El-Sayed, S. Z. Rida, and A. A. M. Arafa, "Exact solutions of fractional-order biological population model,"
Communications in Theoretical Physics, vol. 52, no. 6, pp. 992-996, 2009. 